\title{
Research on an Online and Offline Mixed Teaching Practice Based on Case Study
}

\author{
Ying Zhang, Xiaoxia Li, Ruifang Zhai, Yi Wang* \\ College of Informatics, Huazhong Agricultural University, Wuhan, China \\ *corresponding author e-mail: 7430729@qq.com
}

Keywords: Cast Study; Online and Offline; Mixed Teaching

\begin{abstract}
According to current difficult programming teaching, based on the philosophy of student-oriented, an online and offline mixed teaching practice of case study and multi-integration was proposed. At the same time, it also adopted penetrating case teaching method, inquiry teaching method and competition guiding teaching method to lead and support students' study, yielding remarkable results.
\end{abstract}

\section{Introduction}

Just like Einstein said, education is what learners can keep after forgetting everything they have learned. Besides knowledge and skills that have been learned, the rest are capability, quality and attainment [1-2]. The attainment comes from knowledge and skills but is more important than both of them. Adhering to this teaching philosophy, when teaching the $\mathrm{C} / \mathrm{C}++$ Programming subject, the 3D teaching objectives, such as knowledge and skills, process and method, emotional attitude and values were regarded as the destination, exploring an online and offline mixed teaching practice of case study and multi-integration[3-5].

\section{Penetrating case teaching method}

In order to reach the one-dimensional knowledge and skills teaching objectives, it can help students acquire basic knowledge of $\mathrm{C} / \mathrm{C}++$ programming, write codes, solve actual problems, get familiar with code writing standard and master computing thinking. The knowledge points were introduced by cases to lead student to program and enhance their basic programming skills, which can attract students' attention and show interest in programming[5].

The cases mentioned in the course are to find the rich and interesting practical problems focusing on core knowledge points in each chapter. By writing short code to obtain the solution of those problems, students can quickly find the happiness of learning when the program is approved. Cases such as Mouse Maze, Supermarket Self-Service Cashier System, Ancient Magic Calculation, Police Catching Thief, Link to Guess Game, Tower of Hanoi, Courier in Programming World, Hand-in-Hand Game, Secret in Black Box, Minecraft of Sandbox Games, Cloning in Programming World, “A Rolling Stone Gathers No Moss”, etc. At the beginning, students may feel it was difficult to learn but enjoy themselves finally.

In addition, some comprehensive training projects were designed to run through the whole teaching process. The teacher will divide the maze game and bank account management for detailed explanation. Each time a new knowledge point is learned, a new task will be added to the original version 1.0, which is upgraded to version 2.0 and version 3.0. Students can learn small knowledge points from each case and also from comprehensive cases with several knowledge points. After learning, they need to finish two comprehensive training projects in groups, such as Snake game and enterprise wage management.

\section{Inquiry teaching method}

According to the two-dimensional targets of process and method, through the main training way of 
self-operation on the computer by students, they can have the opportunity to express, question, inquiry and discuss freely, applying cooperative inquiry to solve the problem.

Through popular and interesting cases, a new, interesting, strange and suspicious classroom teaching situation was created for each chapter, in order to stimulate the enthusiasm of students to actively participate in learning and questioning. Meanwhile, the difficult problems of the students can be screened out for giving intensive lectures. The role of students will change from active learning to active listening and thinking, gradually forming a teaching atmosphere in which students can propose questions explained by teachers bravely.

In the classroom, the teacher carefully designed the gradient programming problems from easy to difficult, integrating knowledge with practice, such as inviting five students on stage to simulate bubble sorting process, and conducting competing code of Snake game among groups in the experimental class. Therefore, students can compete with each other in a lively and interesting classroom atmosphere.

In the 4-student group, the leader is responsible for explanation, supervision and inspection of the group members' learning status and other group members need to share their opinions independently and cooperate with each other to deepen the understanding and mastery of the learned knowledge.

After class, teachers assign relevant extension cases such as the postgraduate entrance exams, ACM competition questions, biological information and other extension cases of agricultural science to the learning group, highlighting the expansion and transfer of students' knowledge and ability, and improving the students' ability of comprehensive analysis and problem-solving, in order to obtain multi-dimensional growth.

\section{Competition guiding teaching method}

To promote teaching and learning through competition can not only enhance students' interest in learning, but also explore their talents for selection, which is a good virtuous circle mode.

As the chief coach of ACM competition in Huazhong Agricultural University, the author adopted the competition mode through every link of the course process assessment. First of all, the homework needed to finish in the competition mode, which is set the time limit to submit and the score can be obtained when having submitted it. Secondly, it can combine the real competition questions with the teaching and promote teaching and learning by competition. Finally, students are encouraged to participate in various kinds of programming competitions at all levels, in order to transform their learning achievements in a timely manner, improve their application ability and find the programming talents by exploring students’ potential.

\section{Online and Offline Mixed Teaching}

Before class, students completed the MOOC pre-class test by watching the micro class video, self-learning of PPT and textbooks.

In the class, according to the test results, the teacher can timely adjust the time proportion of teaching content. Through case introduction and coding, the case advancement, problem case and error code correction are realized. Students can practice, consolidate, summarize and reflect in the way of group cooperative exploration. The author thought that the flipped teaching effect would be good, but it was not suitable for all lessons. $50 \%$ of the lessons can still use the traditional teaching mode to explain the programming difficulties.

After class, the students expand the advanced knowledge according to the references provided by the teacher, complete the online homework and group comprehensive projects, and consolidate and review in various forms. Due to many problems and heavy tasks, the students may still ask questions in the QQ group till the midnight, and the teacher will find who cannot keep up with them and help them alone. 


\section{Whole-process assessment method}

The whole-process assessment is proposed to reduce the proportion of final examination to $40 \%$, and increase the proportion of all kinds of assessment to 60\%. It can avoid the phenomenon that students don't study hard in their spare time but cram for exams.

The assessment content is diverse, including: pre-class MOOC test, class attendance, interactive questioning and group sharing and display in the class, MOOC unit test, MOOC interaction in the discussion area, odd-numbered week's ITC computer work, even-numbered week's ITC computer experiment, $\mathrm{C}$ language comprehensive training project, $\mathrm{C}++$ language comprehensive training project, final theory test on computer, final experiment test on computer, etc.

The integration of teaching and examination should be focused, which is to supervise the teaching by means of independent, group and case-based tests, and find out the students' shortcomings in the examination for improving the teaching. The examination should be integrated into students' daily learning to improve their daily learning efficiency. Meanwhile, the assessment and exercise of students' practical ability, comprehensive application ability, team cooperation and innovation ability can also be focused.

\section{Conclusion}

Through case practice, multiple integration, and online and offline mixed teaching, the overall performance of students has improved year by year. More and more students have chosen to participate in various programming competitions, and the number of awards has also increased. Based on online and offline mixed teaching practice of multi-integration based on case study, the teaching can be integrated with industry requirement to stimulate students' learning interest, enhancing theoretical foundation together with discipline competition, and nurturing practical ability with case study. Integrating with the discipline competition to enhance the innovation ability and cultivating the scientific research literacy by scientific research training, it can be combined with the curriculum ideological and political education to lead the value, in order to achieve the three-dimensional goals of emotional attitude and values and help students overcome the fear of programming and obtain a well-trained professionalism. Improving their innovative awareness of eliminating the false and retaining the true, students can pursue a brave spirit to overcome scientific problems continuously.

\section{Acknowledgements}

We would like to thank the Teaching Reform Project in Hubei Province (No.:2018200) for its support.

\section{References}

[1] Xing Lili. The Construction and Empirical Research of Blended Teaching Model Based on Precision Teaching [J]. China Educational Technology, 2020, (9):135-141.

[2] Zhu Xiaoyan, Liu Junnan. The Application of Online and Offline Blended-Learning Model in C language Course [J]. China Computer \& Communication, 2019, 31(24):250-251.

[3] CHEN Cong. Case Teaching Method of the C Programming Course [J]. Fujian Computer, 2020, 36(3):84-86.

[4] ZHU Hongpeng, YUAN Yun. Creating Situations and Case Teaching:New Thoughts on Teaching Reform of Programming Courses [J]. The Guide of Science \& Education, 2019, (30):115-116. 